\title{
Comparative Study of Stress-Strain Characteristic of Peat Soil
}

\author{
A. Zainorabidin ${ }^{1, a^{*}}$ and S. H. Mansor ${ }^{2, b}$ \\ ${ }^{1}$ Associate Professor, Faculty of Civil and Environmental Engineering, University of Tun Hussein \\ Onn Malaysia, Parit Raja, 86400 Batu Pahat, Johore, Malaysia \\ ${ }^{2}$ Research Student, University of Tun Hussein Onn Malaysia, Parit Raja, 86400 Batu Pahat, \\ Johore, Malaysia \\ aadnz7574@gmail.com, bhajarmansor0508@yahoo.com.my
}

\section{Keywords: Direct Simple Shear Test, Direct Shear Test, Stress-strain, Hemic.}

\begin{abstract}
This paper shows the stress-strain behavior of peat from the perspective of geotechnical engineering based on laboratory test. Stress happens when a load applied to a certain specimen and deformed the specimen while strain is the response from applied stress on a specimen. Peat is known as an ultimate soft soil in engineering terms because it has low shear strength and compressibility. This research is concerned about the stress-strain behavior of hemic peat. The undisturbed samples were collected at Parit Sulong and Parit Nipah, Batu Pahat, Johore, Malaysia. Normal stresses are $12.5 \mathrm{kPa}, 25 \mathrm{kPa}, 50 \mathrm{kPa}$ and $100 \mathrm{kPa}$. The shear rate to determine the stress-strain on peat is $0.1 \mathrm{~mm} / \mathrm{min}$. It is a drained condition test. Both results from each method that obtained were compared based on the relationships of stress-strain. Parit Sulong has higher stress-strain than Parit Nipah. If shear stress increased, shear strain also increased. The result shows that, direct simple shear test of stress-strain that tested on hemic is more relevant than a direct shear box because DSS shear the entire specimen of peat while DSB only shear at the center of the specimen. Geotechnical engineers can use the direct simple shear method to understand efficiently about the stress-strain behaviour of peat.
\end{abstract}

\section{Introduction}

Hemic peat is known as soft soil. It can be categorized as problematic soil, because of low shear strength and the determination of shear strength of peat soil is difficult in geotechnical. These soil materials are intermediate in degree of decomposition, shear strength, compressibility and permeability. It contains $33 \%-66 \%$ of fibre. It also contains more water content than amorphous. Peat contains $65 \%$ organic matter or less than $35 \%$ mineral content [4]. This is the reason why the engineer tendency to avoid any construction and building on the soil. There are many challenges on peat soil. It needs high cost to construct a building on peat. Peat has high water content with extraordinary compressibility because it can leads to undesirable of settlement. Settlement can lead to failure. Lack of research has been focused on the stress-strain strength behaviour of peat. Figure 1 shows the sample of hemic peat.

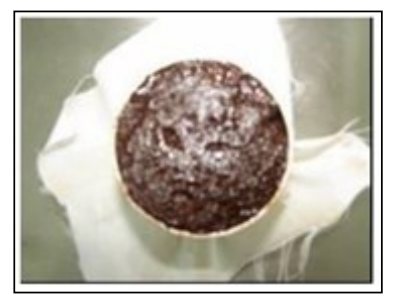

Figure 1 Hemic sample [5]

This research is focused at Parit Nipah and Parit Sulong, Batu Pahat, Johore. Stress-strain strength is the most important thing to know the behaviour of peat. Laboratory testing has become an important part in the peat soil investigation. Direct simple shear was an upgraded device from a direct shear box that is to measure the stress-strain of soil. The direct shear test is an old 
development, while direct simple shear test is a new improvement of the direct shear box. Although both devices can apply shear directly to the soil specimen, the direct shear box test suffers from stress inhomogeneity [3]. Direct simple shear and direct shear box have a different shearing condition that is shown in Figure 2(a) and (b). The shearing condition of DSB occurs at the center of the specimen and shear at the opposite direction while DSS, the entire specimen distorts without the formation of single shearing surface. This research will focus on the differences in the stress-strain measured during direct shear box and direct simple shear tests on peat.

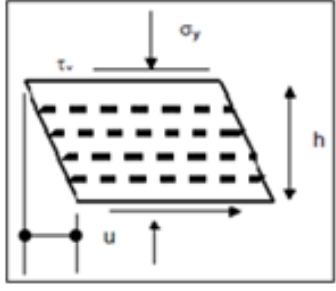

(a)

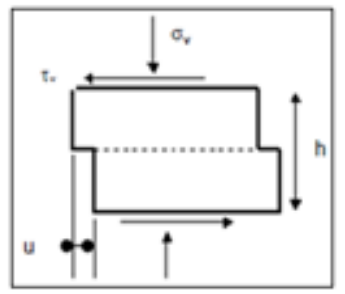

(b)

Figure 2 Conditions of (a) direct simple shear and (b) direct shear box [3]

\section{Stress-strain}

The shear strain, $\gamma_{x y}$ can be measured as $u / h_{0}$ where $u$ is for shear displacement and $h_{o}$ is an initial consolidated specimen height [3]. It is important to maintain the strain rate when comparing test methods. A direct simple shear has the same initial stress state as a direct shear test but avoids the stress concentration occurrence seen with direct shear. The dilatancy component normally disappears when there is no increment of volume after failure occurs [7]. When the stress-strain curves become horizontal, then the friction component is active. For low organic contents and drained test condition the stress-strain behaviour was influenced primarily by the mineral fraction. Soil shear strength may be defined as the shear stress over stress strain. Based on Anggraini (2006), the magnitude of strain depends on load, composition of soil, pass stress history and void ratio [4]. Simple shear is in cylindrical shape that has a series of thin brass confining rings. It obtained more homogenous distribution to shear and normal stresses, and resulting strains. Besides that, the purpose is to apply the specimen with a simple shear strain deformation [2]. Direct simple shear test can shear a soil to unlimited displacement without creating a substantial non-uniformity in stress and strain distributions. It also allows the shear deformation to be distributed uniformly through the sample because of confining rings. Direct shear box is the straightforward and simplest test to determine behaviour of soils. Specimen inside the direct shear box is sheared along the center of the specimen at horizontal plane and shows that the failure plane is horizontal. The specimen is in square shape. There's been a criticized on the direct shear box that relate to the non-uniformity of stress-strain throughout the specimen because of rigid platens that used to confine the specimen as stated from Saada \& Townsend (1981) [3]. Besides that, the shearing happens when one half of the box moves relative to another and will create failure in soil specimen. It might fail the soil on the designated plane, which may not be the weakest one.

\section{Experimental Investigation}

In the investigation of direct simple shear test, normal stresses that have been carried out on undisturbed specimens are $12.5 \mathrm{kPa}, 25 \mathrm{kPa}, 50 \mathrm{kPa}$ and $100 \mathrm{kPa}$. The shear rate is $0.1 \mathrm{~mm} / \mathrm{min}$. The direct simple shear apparatus used in this research is shown in Figure 3(a), (b) and (c). Another test was also performed is a direct shear box. Direct shear box also carried out using the undisturbed specimens with the same normal stresses as direct simple shear. The testing also involved with the same rate of shear, $0.1 \mathrm{~mm} / \mathrm{min}$ and performed under drained condition. Testing procedures and the result data are as follows. 
Direct simple shear was conducted on a cylindrical specimen that retained inside a series of thin rings based on ASTM D 6528-00. A soil specimen is surrounded by a stack of rings. The size of the specimen is $63 \mathrm{~mm}$ in diameter with $30 \mathrm{~mm}$ height. The specimen was soaked with water bath before run the test and applicable to field situation. The specimen is consolidated anisotropically under a vertical stress and deformation by application of shear stress. The specimen was then put into the rings with normal stress applied. The specimen is then sheared from top platen with constant normal stress.

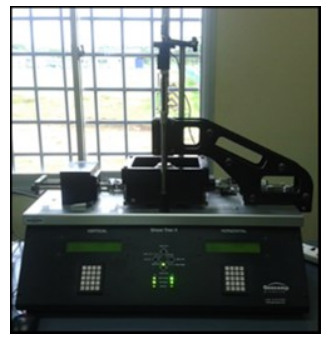

(a)

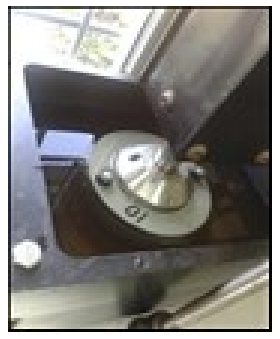

(b)

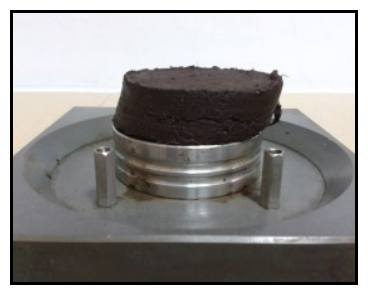

(c)

Figure 3 (a) Simple shear test (b) Specimen in simple shear (c) Peat soil taken out of the stack of rings after the test

The direct shear box test was prepared properly based on BS standard 1377:1990 (Part 7). As shown in Figure 4(a), (b) and (c), the specimen was in square with the size of $60 \mathrm{~mm} \times 60 \mathrm{~mm} \times$ $25 \mathrm{~mm}$. It also was thoroughly saturated with water bath before run the test to have the realistic condition as on the field. The test equipment consists of a metal box which a soil specimen is placed. Porous stones were placed at the bottom and the top of the specimen. Normal stress is applied through a metal plate. The box is split horizontally into two halves. Then, the specimen was put into the shear box with suitable normal stresses and shear rate.

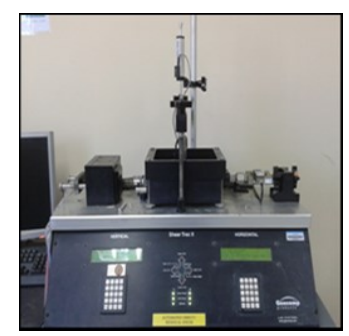

(a)

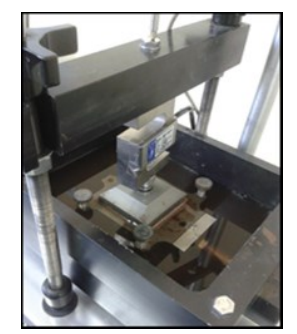

(b)

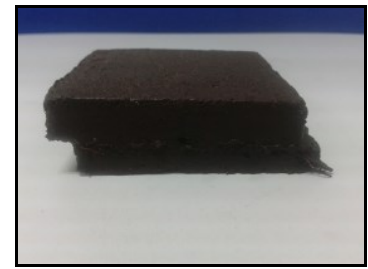

(c)

Figure 4 (a) Direct shear box test (b) Specimen in direct shear (c) Peat soil taken out from the shear box test

\section{Results and Discussion}

The relationship between the shear stress and shear strain obtained from direct simple shear test are shown in Figure 5 between Parit Nipah and Parit Sulong, Batu Pahat, Johore. The different curves are based on different normal stress $(\mathrm{kPa})$ that applied. The shear stress increases with shearing shear strain initially until reaching a peak, after which shear failure occurs, which is signified by a plateau in the stress-strain response. 


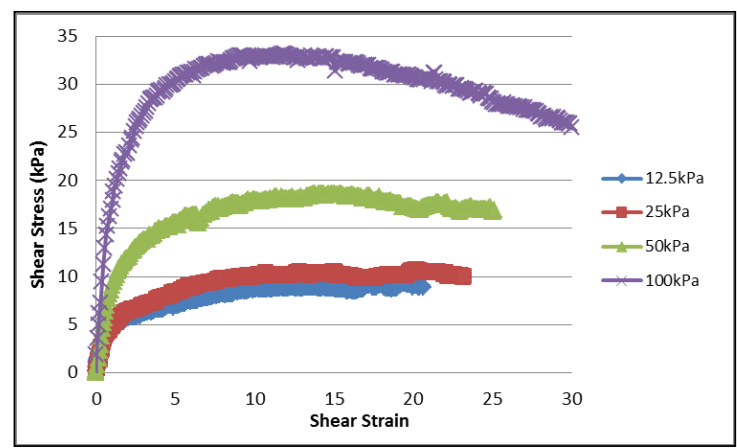

(a)

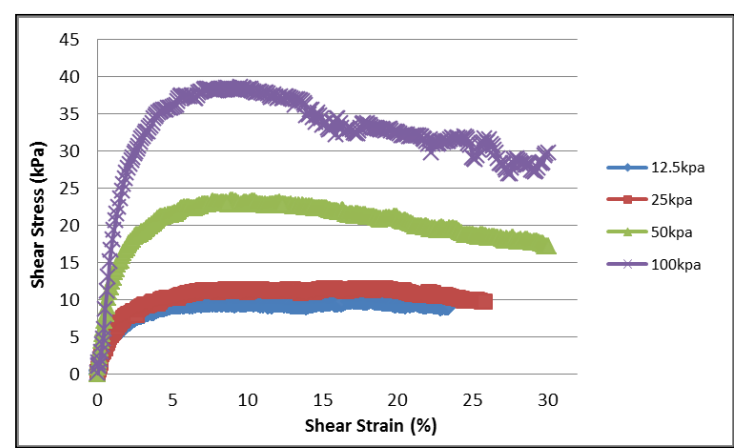

(b)

Figure 5 (a) Parit Nipah (b) Parit Sulong; Stress-strain relationship of peat with different normal stress of $12.5 \mathrm{kPa}, 25 \mathrm{kPa}, 50 \mathrm{kPa}$ and $100 \mathrm{kPa}$ after simple shear

The test involved a change of normal stress to define the stress obtained from the shear box test and presented in Figure 6. It shows that the shear stress is increasing continuously based on the increment of the normal stresses.

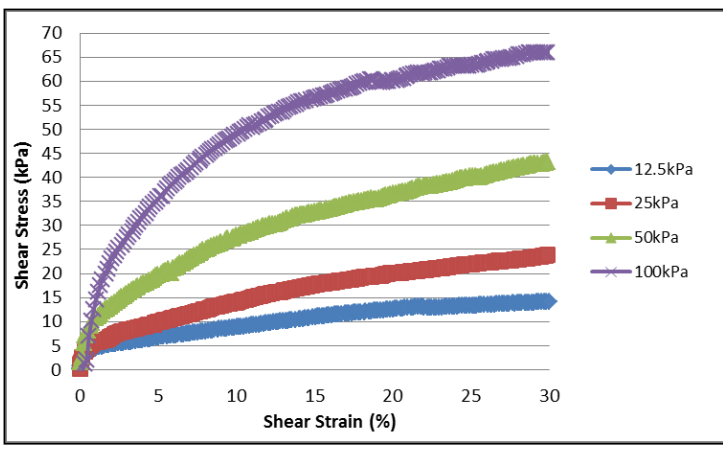

(a)

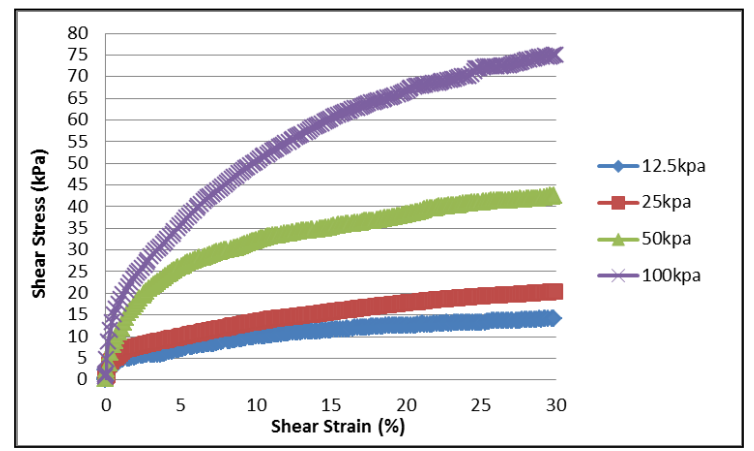

(b)

Figure 6 (a) Parit Nipah (b) Parit Sulong; Stress-strain relationship of peat with different normal stress of $12.5 \mathrm{kPa}, 25 \mathrm{kPa}, 50 \mathrm{kPa}$ and $100 \mathrm{kPa}$ after direct shear box

Peak stress can be found in the constant load test. As shown in this Figure 7, when normal stress increased the stress-strain also increased, probably because of the peat fibre and normal stress that respond on the tested peat. In direct simple shear test, the stresses within the sample are likely to be fairly uniform and give more realistic values. The figure below shows the stress-strain relationship graph at $12.5 \mathrm{kPa}$ and $100 \mathrm{kPa}$ of normal stresses. There are small differences of strains from each stress. It is because the plane failure of the direct shear box is at horizontal plane and at the center of the specimen and may not be the weakest plane. The result that obtained from the direct shear box considered to be straight forward and simple. Fibre in the middle of the specimen will be affected more than the other area of the specimen. This is because of the relative displacement of the two halves of the box.

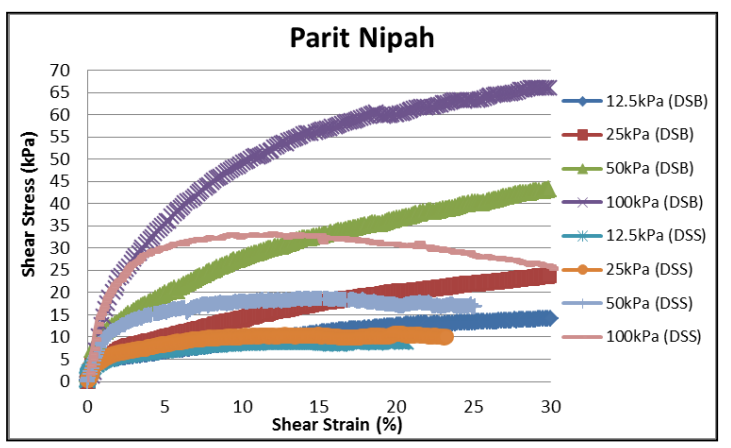

(a)

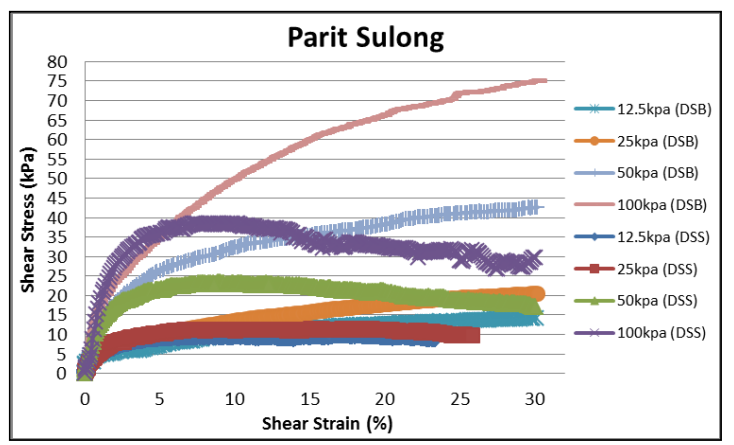

(b)

Figure 7 (a) Parit Nipah (b) Parit Sulong; Comparison between direct simple shear test and direct shear box test 


\section{Conclusion}

The behavior of peat is largely based on its fibrosity and anisotropy. There are differences of shear stresses between direct simple shear test and direct shear box test but shows clear differences in strains. This is because the shear strain homogeneity is increased inside the direct simple shear specimen. Based on the results, direct shear box test gives higher estimates of strengths than direct simple shear. This is because of the different shearing mechanism that imposed to specimen or due to the size of the specimen and the specimen handling manner. The graph of the direct shear box is increasing continuously because of the shearing process that only acting horizontally at the center of the specimen. A direct simple shear graph shows the peak stress of the specimen and finally decreasing because simple shear sheared around the entire specimen. The stress-strain condition from a direct shear box is non-uniform by different type of the mechanism condition of the shear box may create significant effects of shear strength. Furthermore, direct simple shear is useful in investigating stress-strain-strength relationship because of the wider shearing mechanism and more realistic than a direct shear box. Overall, shows that direct simple shear is very interesting and suitable for research of soft soil (peat) in areas where risk of shearing has to be determined.

\section{Acknowledgment}

The author would like to express sincere gratitude to the supervisory team for the encouragement and valuable support and to members of the staff of the Faculty of Civil \& Environmental Engineering Department (UTHM), Research and Soft Soils Centre (RECESS), Fundamental Research Grant Scheme: Vot 1224 (FRGS) and Research, Innovation, Commercialization and Consultancy Office (ORICC).

\section{References}

[1] Grognet, M.: The boundary conditions in direct simple shear tests, development for peat testing at low vertical stress". M.Sc. thesis. Delft University of Technology (2011)

[2] Hanazawa, H., N. Nutt, Lunne, T., Tang, Y.X., and M. Long: "A comparative study study between the NGI direct simple shear apparatus and the Mikasa direct shear apparatus". Soils and Foundations, 47 (1) Japanese Geotechnical Society (2007) p. 47-58

[3] B.B.K. Huat, S. Kazemian, A. Prasad and M. Barghchi: "State of an art review of peat: general perspective". International Journal of the Physical Sciences Vol. 6(8) (2011) p. 1988-1996

[4] A. Katimon and L. Melling: "Moisture retention curve of tropical amorphous and hemic peat". Malaysian Journal of Civi Engineering 19(1) (2007) p. 84-90

[5] I.S. Muhamad, S. Gandaseca, O.H. Ahmed \& N.M.A Majid: Comparison of selected chemical properties of peat swamp soil before and after timber harvesting. Am. J. Environ. Sci., 6(2) (2010) p. 164-167.

[6] O.B. Andersland, A.S. Khattak and A.W.N. Al-Khafaji: " Laboratory shear strength of soil". American Society For Testing and Materials (1981) 